\title{
Aprender, pensar e viver História: Contribuições e questionamentos a partir de um estudo com professores e estudantes brasileiros e paraguaios. ${ }^{1}$
}

\author{
Learning, thinking and living History: Contributions and questions \\ from a study with teachers and sudents from Brazi and Paraguay.
}

\author{
Éder Cristiano de Souza ${ }^{2}$
}

\section{RESUMO}

O presente artigo parte de três pressupostos elementares: 1 . Ensinar história é lidar com conhecimentos que se relacionam à vida em sociedade; 2 . Professores de história são sujeitos partícipes $d$ a sociedade, portanto suas vidas são afetadas por histórias que aprendem e ensinam, ou tentam ensinar; 3. Aprender história não é um ato individual isolado, pois não pode ser desvinculado da vida em sociedade, e não se limita a procedimentos metodológicos e conceituais restritos à sala de aula. A partir desses pressupostos, apresenta um debate sobre as relações entre a aprendizagem histórica, qualificada nos fundamentos do pensamento histórico, a função orientadora da história na vida e a concepção de formação histórica, a partir da forma como essas questões se apresentam nos estudos da Educação Histórica e da Didática da História. E relata um estudo realizado com professores e estudantes, de licenciatura em história, brasileiros e paraguaios, a partir dos conceitos objetividade e multiperspectividade, tendo como base interpretações divergentes sobre um conteúdo histórico específico, a Guerra da Tríplice Aliança. Os resultados desse estudo permitem elaborar reflexões sobre conceitos relevantes para discutir o ensino de história na atualidade: cultura histórica, burdening history, identidades e objetividade histórica.

Palavras-chave: Aprendizagem Histórica. Formação Histórica. Cultura Histórica. Objetividade. Multiperspectividade.

\footnotetext{
${ }^{1}$ Pesquisa desenvolvida no âmbito do projeto de pesquisa "Didática da História, Cultura Histórica e Indústria Cultural: Perspectivas desde e sobre a América Latina”, que conta com apoio financeiro do PAIP - Programa de Auxílio à Integração de Docentes e Técnicos Administrativos às Atividades de Pesquisa, da PRPPG-UNILA.

${ }^{2}$ Docente do curso de História da UNILA - Universidade Federal da Integração Latino-Americana. Foz do Iguaçu - PR. Email: eder.souza@unila.edu.br.
} 


\section{ABSTRACT}

This article is based on three basic assumptions: 1. Teaching history, is dealing with knowledge that relate to life in society; 2. history teachers are subject participants of society, so their lives are affected by stories they learn and teach, or try to teach; 3 . Historical learn is not a single isolated act, it can not be divorced from life in society, and is not limited to methodological and conceptual procedures restricted to the classroom. From these assumptions, it presents a discussion on the relationship between the historical learn, qualified on the fundamentals of historical thought, the guiding role of history in life and the concept of historical formation, from the way these issues are presented on the studies of Historical Education and Didactic of History. And reports a study with teachers and students, of degree in history, Brazilians and Paraguayans, from the concepts of objectivity and multiperspective, based on differing interpretations of a specific historical content, the Triple Alliance War. The results of this study allow us to draw reflections on relevant concepts to discuss the teach of history today: historical culture, "burdening history", identity and historical objectivity.

Keyword: Historical Learning. Historical Formation. Historical Culture. Objectivity. Multiperspective.

\section{Apresentação}

O presente artigo parte de três pressupostos elementares: 1 . Ensinar história é lidar com conhecimentos que se relacionam à vida em sociedade; 2. Professores de história são sujeitos partícipes da sociedade, portanto sua vida é afetada pelas histórias que aprendem e ensinam, ou tentam ensinar; 3. Aprender história não é um ato individual isolado, pois não pode ser desvinculado da vida em sociedade, e não se limita a procedimentos metodológi cos e definições conceituais restritos à sala de aula.

Apesar de essas formulações serem lugares-comuns entre os especialistas, e mesmo não especialistas, que se preocupam com o ensino de história, algumas formas de abordagem dessas questões são limitadoras. Essas limitações têm a ver com três enquadramentos predominantes: 1. Pensar o ensino de história a partir de preocupações puramente metodológicas, isolando o objeto da aprendizagem do sujeito da aprendizagem; 2 . Pensar a aprendizagem histórica focada na ideia de assimilação (leia-se memorização) de conteúdos históricos (leiam-se informações); 3. Abordar a aprendizagem histórica somente como desenvolvimento de competências de interpretação histórica.

No primeiro caso, é comum propor-se que há defasagem no ensino de história por ausência de inovações metodológicas, e buscam-se estímulos que favoreçam a o interesse pela aprendizagem, ou seja, busca-se "dinamizar" as estratégias de ensino para melhorar a aprendizagem. Já no segundo, entende-se que aprender história é ampliar a bagagem de informações sobre o passado, por isso parte-se do pressuposto que é preciso renovar os 
conteúdos históricos, tornando-os mais atualizados em relação à historiografia e aos problemas do presente.

Por fim, no terceiro caso, pressupõe-se que aprender história é desenvolver raciocínios qualificativos das formas como acessamos informações sobre o passado. Nesse caso, a aprendizagem é entendida como desenvolvimento de competências cognitivas para compreensão do passado, como o lidar com evidências e fazer inferências históricas, estabelecer relações de temporalidade, desenvolver empatia histórica, compreender a possibilidade de múltiplas interpretações do passado.

Nenhum dos três enquadramentos predominantes responde integralmente às problemáticas inicialmente levantadas, apesar de contemplarem parcialmente suas demandas. Isso porque, primeiramente, é preciso ter em conta que há uma relação muito estreita entre todos os elementos que compõe o processo de aprendizagem histórica: metodologias de ensino, conteúdos de aprendizagem e formas de interpretação. Esses três elementos, além de não poderem ser tratados isoladamente, também não podem se desvincular de um quarto elemento, que foi apontado nos pressupostos teóricos inicialmente levantados: a relação entre aprendizagem histórica e vida em sociedade.

Esses apontamentos iniciais obviamente tratam de questões muito amplas e genéricas, necessitando de aprofundamento em cada uma das problemáticas levantadas, a fim de esclarecer efetivamente quais são as limitações e possibilidades apontadas. Como isso não é viável, do ponto de vista dos limites de um artigo científico, optamos por centrar a reflexão em dois pontos, que contribuirão para entendimento das questões colocadas.

Primeiramente, apresenta-se um debate sobre as relações entre a aprendizagem histórica, qualificada nos fundamentos do pensamento histórico, e a função orientadora da história na vida, e também sobre a concepção de formação histórica, a partir da forma como essas questões se apresentam nos estudos da Educação Histórica e da Didática da História.

No segundo ponto, apresenta-se um breve estudo realizado com professores e estudantes, de licenciatura em história, brasileiros e paraguaios, a partir dos conceitos objetividade e multiperspectividade, tendo como base interpretações divergentes sobre um conteúdo histórico específico, a Guerra da Tríplice Aliança. Os resultados desse estudo permitirão elaborar algumas reflexões sobre conceitos relevantes para discutir o ensino na atualidade: cultura histórica, burdening history, identidades e objetividade histórica. 


\section{Um debate sobre aprendizagem histórica e orientação da vida}

Na Inglaterra, há pelo menos três décadas, surgiu um conjunto de estudos, sobre aprendizagem histórica, que se diferenciava de estudos sobre cognição fundamentados em teorias advindas da psicologia da aprendizagem. Nesses estudos, os pesquisadores objetivaram investigar a capacidade de crianças e jovens aprenderem não apenas os conteúdos históricos, denominados conceitos substantivos, mas também categorias específicas da produção do conhecimento histórico, chamadas de conceitos de segunda ordem (LEE, 2006; ASHBY, 2006).

As pesquisas surgidas na Inglaterra influenciaram investigações em vários países, especialmente Portugal e Brasil, há pelo menos uma década e meia. Os resultados desses trabalhos permitiram romper com ideias tradicionalmente aceitas, dentre elas a de que aprender História é acumular informações sobre o passado, e também que níveis de complexidade do conhecimento ensinado se vinculam diretamente a etapas de desenvolvimento cognitivo. Essas investigações mostraram como crianças e jovens podem mobilizar ideias históricas, raciocinando a partir de conceitos complexos, em um nível até então não esperado para suas idades (SCHMIDT; BARCA, 2009).

Contudo, especialmente no caso brasileiro, os estudos da Educação Histórica não se limitaram à influência de modelos teóricos e metodológicos ingleses, e buscaram amparo em outros referenciais. Esse diálogo se deu com os estudos de pesquisadores alemães da Didática da História, difundidos no Brasil a partir da publicação dos trabalhos de Klaus Bergmann (1990), Jörn Rüsen (2001, 2007), Bodo Von Borries (2012). Esses trabalhos preocupam-se não apenas com a forma como ocorre a aprendizagem histórica, mas também com as implicações dessa aprendizagem para a orientação da vida em sociedade, com especial atenção ao conceito de consciência histórica (GERMINARI, 2011).

Tendo como base esses estudos, proponho agora uma reflexão teórica em base em algumas de suas temáticas centrais, principalmente sobre a relação entre uma aprendizagem histórica de conceitos organizadores do pensamento histórico, e a efetiva mobilização desses conceitos na orientação da vida em sociedade. Utilizarei como suporte os trabalhos de Peter Lee (2011), Jörn Rüsen (2001) e Bodo Von Borries (2011).

Peter Lee (2011) entende que a compreensão histórica deriva e é impulsionada pela aquisição de determinadas disposições, dentre as quais a de produzir os melhores argumentos possíveis para quaisquer histórias que contamos. Tais argumentos nascem de perguntas e pressuposições, que dão origem à necessidade de apelar para a validade das histórias e a verdade das declarações factuais singulares. E entre essas disposições, Lee 
destaca também que se torna possível reconhecer a importância das pessoas do passado, de forma respeitosa, entendendo-as como seres humanos, não manipulando suas histórias de acordo com conveniências e interesses.

Há então o princípio da orientação histórica, que se relaciona a um duplo enquadramento do conhecimento. Um conjunto de feitos do passado, que poderia ser entendido como um quadro de orientação que tornaria possível a compreensão do mundo presente como resultante desses feitos. E também um conjunto de raciocínios complexos, a partir dos quais os sujeitos estariam aptos a lidar com o passado com base em categorias essenciais a uma racionalidade propriamente histórica.

Segundo Lee a História é "contraintuitiva", pois seu entendimento exige que os sujeitos modifiquem, ou mesmo abandonem, ideias do senso comum, pois essas ideias cotidianas tendem a impossibilitar a compreensão do passado. Sua aprendizagem contribui com a vida dos sujeitos, pois envolve lidar com um aparato de conceitos de segunda ordem, que lhes permita perspectivar a História a partir da noção de mudança, superando as visões cotidianas que naturalizam o entendimento da realidade e abordam o passado como fixo e isolado no tempo (LEE, 2011).

Essa possibilidade de perspectivar historicamente o próprio conhecimento de mundo, a partir de critérios específicos de validação dos argumentos, é uma das bases fundamentais para a concepção de cognição histórica que direciona os estudos da Educação Histórica. Uma história que possibilite a cada sujeito a elaboração de quadros utilizáveis do passado, que superem suas antigas concepções baseadas em argumentos rasos e raciocínios imediatos, seria então transportada para a vida.

Literacia Histórica é o conceito utilizado por Lee (2006) para definir os objetivos do ensino de história. Esse conceito pode ser sintetizado como um conjunto de competências cognitivas que adquiridas possibilitem aos sujeitos tratar o passado como um sistema de conexões temporais, que abarquem uma gama aberta e indefinida de histórias, e não simplesmente um uso do passado vinculado a interesses. Determinados padrões intelectuais, níveis de reflexão e critérios são exigidos para que se atinja um raciocínio histórico bem-sucedido. Lee (2011) entende então que a escola, mesmo tendo que atender a determinadas exigências não aplicáveis à história acadêmica, não pode deixar de ensinar aos alunos as normas e critérios a partir dos quais a História é construída.

Nesse sentido, o autor propõe que seja desenvolvida uma compreensão conceitual complexa, e não simplesmente determinadas habilidades devam ser treinadas para resultados diretos e práticos. Aprender História é então entendido como um exercício de reorientação cognitiva, que permite aos alunos ver o mundo de maneiras novas e mais bem elaboradas, transformando suas visões e permitindo a mobilização de perspectivas de ação até então inconcebíveis, especialmente ao apontar para o que pode ser esperado, e fazer 
evidente como nem sempre o que se espera é o que se realiza, gerando a compreensão da amplitude de possibilidades da vida. Permitir aos alunos ver o mundo historicamente, a partir do pensamento fundamentado na epistemologia da História, seria assim um exercício transformador no campo da Educação Histórica (LEE, 2011).

Esse movimento de interpretação da História, que gera perspectivas e expectativas em relação à vida prática, é teorizado por Jörn Rüsen (2001), que aponta para o movimento essencial da aprendizagem histórica istórica como um processo no qual as experiências aumentam e são qualificadas a partir de determinadas interpretações, que apontam para um futuro esperado, gerando um horizonte de expectativas que orienta a definição das identidades e na motivação para o agir.

Nesse sentido, Rüsen propõe que a aprendizagem é mobilizada por aqueles conteúdos ligados às experiências advindas da realidade vivida pelos sujeitos e à interpretação desta a partir de perspectivas históricas. A aprendizagem histórica então se trata do desenvolvimento da consciência histórica como um processo no qual o sujeito mobiliza novas concepções, amplia sua compreensão da experiência temporal e se torna apto a argumentar sobre sua interpretação e sobre a orientação dela derivada.

Ao constituir uma memória histórica, ou seja, um arcabouço estruturado de narrativas que possibilitem a organização mental da existência temporal humana, o sujeito se percebe inserido num mundo histórico, que o precede e ultrapassa, e pode dar significado a essa sua presença, ou seja, essa memória histórica se integra a sua memória pessoal. As narrativas, ou histórias que lhes são contadas, permitem um superar constante de concepções individualistas e auto referenciadas de mundo, possibilitando a ampliação do horizonte cognitivo, a partir do reconhecimento do outro e dos vínculos que os conectam à sociedade e à humanidade.

As reflexões de Lee e Rüsen se aproximam, no sentido de definir que o aumento da capacidade de compreensão e argumentação histórica, a partir de competências qualificadoras do pensamento histórico, possibilita aos indivíduos um crescimento cognitivo que os tornaria mais preparados para orientar-se na vida em sociedade.

Contudo, as proposições de Lee (2011), que de maneira geral refletem a abordagem epistemológica da history education inglesa, definem que a progressão da aprendizagem histórica significa a sofisticação de raciocínios conceituais vinculadaos à validação dos argumentos sobre o passado. Nessa direção, o princípio orientador da vida prática situa -se na progressão de níveis conceituais, o que redunda na ampliação da possibilidade de os sujeitos analisarem o mundo de forma crítica e reflexiva.

Já Rüsen (2007) entende que a progressão da aprendizagem histórica se dá no desenvolvimento de uma competência narrativa. Esse conceito se refere à capacidade de um 
indivíduo construir argumentos que vinculem a experiêncai narrada a uma interpretação com vistas à gerar expectativas orientadoras, vinculando essa narrativa à constituição de suas identidades e à orientação do seu agir.

Nesse sentido, a aprendizagem histórica se daria com a assimilação e internalização de conteúdos, ou experiências temporais, desenvolvendo uma argumentação com vistas a orientar-se na vida em sociedade. O desenvolvimento dessa competência narrativa se daria por mudanças qualitativas na consciência histórica subjetiva.

Tendo em vista essas duas matrizes teóricas, sem optar por nenhuma delas a priori, propõe-se os seguintes questionamentos: 1 . Quais as possibilidades de uma pragmática da Didática da História centralizada na ideia de orientação da vida? 2. Qual o conceito de formação histórica pode fundamentar a Didática da História? Em seguida tentaremos discutir esse conceito de formação, mas sem buscar uma concepção definitiva, com o intuito para apontar para as problemáticas teóricas refletidas no estudo empírico que será apresentado e analisado ao final deste artigo.

\section{Reflexões sobre formação histórica}

Para pensar a concepção de formação, é interessante partir da concepção de Theodor Adorno (1996), que enxerga uma crise geral na formação cultural na sociedade pósindustrial. O teórico alemão corrobora, assim , com a ideia que o capitalismo constitui um padrão elitista de formação cultural, ao qual as classes trabalhadoras não tem acesso, devido à super-exploração do trabalho. E mesmo as classes médias e altas abdicam dessa formação, por se tratar de uma sociedade onde prevalece uma lógica utilitarista de formação.

Adorno reivindica uma formação que estabeleça vínculos com a vida em sociedade, para além da concepção de cultura como o cultivo do espírito, ou a erudição dos sábios. Contudo, entende também que esses vínculos devem ir além de entender a cultura como uma conformação à vida real vinculada estritamente à ideia de adaptação, pois é necessária a educação pela própria vivência social, o que exige certo nível de aquisição cultural.

Por fim, ressalta-se no pensamento de Adorno a noção que a formação cultural, como finalidade da educação, deve superar as próprias condições objetivas nas quais se insere o processo educacional. Ou seja, as condições dadas pelo sistema capitalista também precisam ser combatidas, e não deve cair-se na ilusão de uma educação que por si só seja capaz de formar sujeitos totalmente autônomos e críticos, libertando-os da opressão. 
O conceito de formação histórica, que é trabalhado por Rüsen (2010), parte do pressuposto que é preciso reestabelecer a finalidade do ensino de história, com o fim último da emancipação dos sujeitos. Apesar de entender a força da crítica de Adorno a uma ideia de formação pura, capaz de libertar os sujeitos das condições de opressão, apresenta -se aqui as reflexões de Rüsen como referências para um debate aprodundado, sobre o que significa formar historicamente, e sobre os próprios limites da escolarização em realizar essa tarefa.

No ensino, Rüsen (2010) evidencia dois tipos de formação, sendo a primeira compensatória e a segunda complementar. Na primeira, há uma desvinculação em relação ao conhecimento de referência, à totalidade do agir humano e à superação das carências de orientação para a vida prática. Nesse caso, dimensões pragmática e normativa da didática da História se distanciam dos fundamentos teórico-filosóficos desse campo de referência. Por isso se torna frequente recorrer a métodos, objetivos, estratégias e formas de ensinar que não dão conta de suprir carências de orientação dos indivíduos. A relação com um passado morto ou prático é forma mais frequente de manifestação da formação compensatória no ensino da História. Por haver um distanciamento da ciência de referência, a didática se utiliza de subterfúgios e artifícios que mantém aparência de formação, mas perde sua essência.

Já no âmbito da formação complementar, Rüsen (2007, p. 97) demonstra a possibilidade de levar o sujeito a construir seu próprio ponto de vista a partir de critérios científicos. Essa se efetiva quando o ensino se vincula à reflexão sobre regras e princípios nos quais as ciências categorizam a vinculação entre experiência da totalidade, da práxis e da subjetividade.

Essa dimensão, no caso da História, vai além de aprender regras ou desenvolver competências científicas, como analisar fontes ou estabelecer marcos temporais. Ela tem uma vinculação direta com o todo da experiência humana no tempo, que se torna singular nas operações mentais da consciência histórica. Para compreender essa dinâmica do conceito de "formação complementar", na qual a aprendizagem se estabelece num processo de ação comunicativa que induz identidades e práxis para além de padrões esquemáticos ou estáticos de definição do conhecimento, é preciso entender melhor essa diferenciação entre cognição situada no interior da ciência de referência e aprendizagem alienada dessa vinculação.

István Mèszáros (2008) reivindica uma educação plena para a vida dos sujeitos, que fuja à lógica de subjetivação dos indivíduos que serve ao capital. A formação compensatória é base desse sistema, que fragmenta o ensino em especializações técnicas e pragmáticas, que se desvinculam dos fundamentos das ciências de referência. Nesse contexto, a internalização das regras do sistema capitalista e a subjetivação dos indivíduos a essa lógica é função cumprida pelos sistemas de ensino, que compartilham de técnicas e métodos que renunciam a essa vinculação integral com o campo científico. 
Maria Auxiliadora Schmidt (2009) chama esse processo de sequestro de cognição, uma vez que indivíduos são privados de aprendizagem histórica preocupada com a orientação, e são levados a uma aprendizagem que privilegia acúmulo de informações históricas vazias de sentido. Bodo Von Borries (2009) evidencia como, nesse processo, a História é vista como conjunto global de conhecimentos canônicos, difundidos no processo de escolarização, mas não são internalizados pelos indivíduos, sendo tomados apenas em seu sentido utilitari sta, que se refere a acumular informações que servirão para garantir aprovações nos exames, e que serão descartadas da memória quando não forem mais úteis.

Essa aprendizagem histórica utilitarista tem vinculação direta com a reprodução do sistema capitalista de produção. Indivíduos são treinados, no interior da cultura escolar, a assimilar dados e informações que tem utilidade imediata, mas que não servem à sua formação integral. Pensar na cognição histórica situada é fugir a esse padrão e propor uma ideia de formação histórica integral e profunda, fundamentada em pressupostos teórico filosóficos bem definidos (SCHMIDT, 2009).

O desafio tem sido fundamentar a construção de um conjunto de conteúdos, objetivos e procedimentos que possibilitem uma espécie de alfabetização histórica dos sujeitos (LEE, 2006). Tal concepção se vincula ao objetivo de interconectar dados empíricos, preceitos normativos e estratégias pragmáticas para que o ensino de História passe a se orientar por padrões e critérios específicos que fundamentem a ideia de formação histórica.

A cognição histórica situada seria, portanto, aprendizagem na qual informações sobre o passado são transformadas em conhecimento histórico, a partir de uma articulação complexa entre experiências do tempo e exploração de suas múltiplas significações, no sentido de possibilitar aos sujeitos uma aprendizagem complexa e densa no interior da ciência da História (SCHMIDT, 2009).

Sendo assim, segundo Rüsen (2010) a formação histórica não poderia se desvincular da própria ideia de consciência histórica. Esse sentido formativo se estrutura na relação entre a experiência da totalidade, a práxis e a subjetividade no tempo, ou seja, os sujeitos precisam constituir uma relação com o conhecimento histórico que possibilite essas interconexões com a totalidade da vida humana. Dessa forma:

[...] a formação histórica como totalidade é construída quando os sujeitos "dominam o contexto de suas circunstâncias e condições historicamente situadas no tempo, articulando assim um horizonte de “interpretações" históricas. A partir disso, é necessário que seja considerada a radicalidade da apreensão dos processos cognitivos do pensamento histórico, que capturam a experiência do tempo. Essa 
apropriação cognitiva acontece por meio das categorias históricas também chamadas de conceitos meta-históricos -, as quais são formas do pensamento que buscam o universal no particular do pensamento histórico e procuram a História dentro das múltiplas histórias. Essas categorias históricas (temporalidades, periodizações, processos históricos, explicações, evidências, etc.) são a expressão da totalidade, são os "fios condutores" da integração dos conteúdos ou conceitos históricos ligados à práxis e às orientações do agir (RÜSEN, 2001).

A formação histórica contempla uma relação estreita com a ciência de referência, pois vai além de assimilar informações históricas, e situa-se na interconexão entre aprender conceitos históricos substantivos e de segunda ordem (LEE, 2006), ou seja, a totalidade da formação histórica se completa quando indivíduos tomam conhecimento das experiências a partir de uma compreensão mais bem elaborada, na qual aprendem categorias históricas que tornam mais complexa essa aprendizagem e também são capazes de inserir esse conhecimento na orientação de sua identidade e práxis (RÜSEN, 2007).

A formação histórica permitiria aos sujeitos algumas operações fundamentais: 1. Compreender narrativas históricas e situá-las no fluxo temporal; 2. Interpretar experiências temporais de uma forma aberta, fundamentada em critérios mínimos de plausibilidade, racionalidade e intersubjetividade; 3 . Construir identidades abertas e plásticas a partir da aprendizagem histórica, tomando como referência intersubjetividade no processo de autocompreensão; 4. Orientar sua práxis no sentido de reconhecimento da alteridade do tempo, sendo capaz de construir quadros temporais amplos e sustentáveis a partir de argumentos validáveis (VON BORRIES, 2009).

O desenvolvimento desse conjunto de competências narrativas, que permitam ao indivíduo elaborar explicações fundamentadas numa racionalidade histórica, é objetivo central do conceito de formação histórica, orientador do campo de estudos da Educação Histórica.

Contudo esse objetivo não se trata de fator normativo/prescritivo fundamentado em abstrações teóricas puras. Estudos empíricos têm justamente a função de testar teorias e reformular concepções. Portanto a teoria da consciência histórica é referencial analítico importante, mas não se deve restringir-se à sua aplicação pura e simples, sem propor estudos e reflexões a partir de situações reais de aprendizagem, que problematizem a teoria e contribuam com reflexões inovadoras a partir de condições específicas de ensino.

Tomando como base essas reflexões, apresentam-se, na sequência, algumas reflexões sobre objetividade e multiperspectividade no pensamento histórico. Isso porque, com base 
nessas categorias, será apresentado o estudo empírico realizado, e serão analisados seus resultados com a partir de algumas problemáticas e desafios para as pesquisas sobre aprendizagem histórica e orientação da vida prática.

\section{Objetividade e multiperspectividade}

A partir das reflexões gerais anteriormente apresentadas, pretende-se agora estabelecer o foco em uma mais específica. Se uma aprendizagem histórica que oriente a vida dos sujeitos deve primar por uma racionalidade fundada no pensamento histórico, alguns conceitos são centrais para esse debate. Destaco agora os conceitos de verdade, objetividade e multiperspectividade, evidenciando como geram conflitos de interpretação e é preciso apontar para novas acepções, que tenham como finalidade os usos da história na vida em sociedade, ou seja, a cultura histórica.

No século XIX, foram criadas regras e métodos com a intenção de estabelecer a validade universal do conhecimento histórico, tendo como ponto de partida a concepção de objetividade. Sendo assim, a "objetividade passou a significar, pois, a validade geral do conhecimento histórico, baseada na relação com a experiência do passado e na racionalidade do tratamento cognitivo dessa experiência" (RÜSEN, 2010, p.130).

Essa noção de objetividade, contudo, não é consensual, pois muitos estudiosos da história problematizam distintas formas de compreensão dos limites e da possibilidade de se produzir um conhecimento histórico mais próximo da verdade, ou seja, mais objetivo. Reis (2006) define duas formas principais de enquadrar essa questão: 1. A perspectiva realista, que defende a possibilidade de se chegar a um conhecimento objetivo dos fatos do passado; 2. A perspectiva nominalista, que entende como impossível conhecer esses fatos de forma objetiva, e limita a objetividade histórica aos métodos empregados na produção do conhecimento.

As duas visões trazem problemas em suas concepções. A perspectiva realista leva à ideia de que é possível que se construam conhecimentos verdadeiros e seguros a respeito do passado, criando a noção errônea de que é possível anular, ou isolar, a parcialidade das fontes e as subjetividades do olhar daquele que relata o passado. Já a perspectiva nominalista entende que a verdade sobre o passado jamais será conhecida, pois só é possível existirem visões parciais, e assim o conhecimento do passado gera conflitos insolúveis, já que se torna impossível que uma explicação histórica tenha uma garantia maior de validade para sustentar argumentos. 
Rüsen (2001) propõe uma discussão que vai além dessas problemáticas, e para isso define três critérios distintos de verdade no pensamento histórico. O primeiro critério é chamado objetividade de fundamentação, no qual a possibilidade de chegar a um conhecimento mais verdadeiro do passado se daria mediante a acumulação de conhecimentos, de critérios de análise e de investigações sobre os fatos. Não obstante, nesse caso, o progresso das investigações científicas não ocorre de maneira independente em relação às carências e interesses dos investigadores, que podem transpor tais carências ou interesses às suas interpretações históricas.

O segundo critério é chamado objetividade de consenso, no qual a proximidade com a verdade histórica se daria mediante a possibilidade de haver encontros de pontos de vista. Ademais, que as significações históricas do passado sejam estabelecidas com o reconhecimento da validade das distintas interpretações com um mínimo de proximidade. O problema é que o consensual não sobrevive quando distintas perspectivas são marcadas por interesses e carências divergentes, que geram conflitos. Quando alguém não aceita consensos mínimos e não recua em suas posições, a comunidade científica tende a excluir sua interpretação. Isso não significa que esta não seja possível ou não esteja próxima da verdade histórica, e sim que não está de acordo com as carências e interesses dos outros sujeitos que detém o controle da produção do conhecimento e estabelecem critérios de verdade.

Para superar esses dois critérios, Rüsen (2001) propõe uma alternativa, que chama de objetividade construtiva. De acordo com essa proposição, os argumentos históricos devem articular seus sentidos com as identidades de seus destinatários, sob a ideia regulativa de humanidade como comunidade universal de comunicação. Isso porque:

[...] as representações de continuidade do pensamento histórico que concorrem para a constituição da identidade fundam-se em determinadas ideias que fazem do tempo uma determinação de sentido para a existência humana. Essas ideias decidem sobre a consistência temporal da identidade humana: elas definem o que os homens entendem por si mesmos quando se afirmam como duradouros no fluxo do tempo. (RÜSEN, 2001, p. 143).

A objetividade histórica deve submeter-se a um princípio regulador da necessidade de comunicação humana, e as visões partidárias e parciais precisam estabelecer pontos de convergência, respeitando a multiperspectividade e reconhecendo os limites de cada perspectiva, entretanto sem fugir de possíveis e necessários questionamentos. 
As ideias empregadas pelos historiadores não precisam ser universalmente válidas. Mas é necessário um critério de avaliação sobre sua utilidade significativa para orientação prática. Esse critério só pode vir do próprio processo de metodização do conhecimento histórico, que deve ser orientado a partir de um ideal de organização de um conhecimento histórico científico. (RÜSEN, 2001, p. 145).

Rüsen defende, então, que a subjetividade e a parcialidade das perspectivas históricas, quando confrontadas com outras visões, devem ser reguladas pela noção de orientação da práxis humana. Então, a perspectividade não pode ser entendida como partidarismo, e sim como um ponto de vista que necessariamente precisa estar fundamentado em critérios de validação, enquanto também está aberto ao confronto com outras perspectivas, o que pode garantir o progresso do conhecimento para a orientação da vida prática.

Contudo, essa fundamentação da objetividade histórica necessita estar assentada em três critérios para converter-se em construtiva: pertinência empírica, pertinência normativa e pertinência narrativa. A primeira tem a ver com a existência de fontes, vestígios e evidencias que podem garantir a validação da narrativa como experiência humana. A segunda é regulada pelos critérios de interpretação das evidências históricas, garantindo sua validade mediante análises críticas e perspectivas possíveis a partir dos vestígios disponíveis.

Por fim, a terceira forma de pertinência tem a ver com a definição de sentidos que possam servir à orientação da vida prática. É possível que duas perspectivas sejam baseadas em conjuntos válidos de fontes e evidências, e também sigam padrões rígidos de interpretação histórica, e, ainda assim, produzam narrativas que entrem em choque e gerem conflitos. Nesse caso, faz-se necessário adotar o terceiro critério de pertinência, ou seja, a narrativa. Esse critério de validação tem a ver com a forma como as narrativas apontam para a solução de conflitos, gerando sentidos interpretativos do passado que apontem para um futuro que respeite as identidades presentes, e que possibilite suplantar os conflitos apontando para formas de conciliação.

Essa discussão sobre a relação entre perspectividade e objetividade no conhecimento histórico é central para o trabalho que aqui se desenvolve. Isso porque, as narrativas a respeito da assim chamada Guerra do Paraguai ainda hoje ecoam de forma muito retumbante, especialmente na cultura histórica da nação paraguaia.

Por mais que haja considerável número de investigações históricas, dos mais distintos matizes, a respeito do maior conflito internacional da história do continente americano, há 
uma clara distinção na presença das narrativas a este respeito nos países vizinhos. Uma rápida comparação entre como cada país rememora o conflito, seja por meio da educação formal, seja nos espaços de memória coletiva ou nos meios de comunicação, já permite evidenciar esse confronto de perspectivas.

A discussão sobre a inevitabilidade da perspectividade no pensamento histórico, e a necessidade de busca por uma pertinência narrativa com vistas a uma objetividade construtiva, ainda é um desafio para avançar no sentido de superar conflitos e confron tos no processo de constituição das identidades, especialmente na fronteira Brasil - Paraguai, lugar onde esse estudo foi realizado. Não se pretende apontar soluções À questão, mas refletir sobre um estudo empírico, que será apresentado na sequência.

\section{Um estudo sobre multiperspectividade e objetividade nas ideias históricas de professores e estudantes brasileiros e paraguaios}

Como visto, a perspectividade é condição primaria do conhecimento. A impossibilidade de fazer ressurgir o passado aos olhos do presente, leva à eterna dúvida em relação à possibilidade de ser produzido um conhecimento objetivo do passado. Como o conhecimento está sempre condicionado pela existência de fontes fragmentárias e parciais sobre os fatos ocorridos, cada visão sobre esses vestígios é uma perspectiva parcial, que leva a interpretações particulares.

Os conflitos surgem quando são necessários conhecimentos históricos para dar sustentação aos argumentos. Mesmo reconhecendo a multiperspectividade, é preciso escapar da armadilha de crer na equidade dos distintos olhares e negar a possibilidade de tratar a história como conhecimento com certos níveis de objetividade.

Partindo dessa problemática, a investigação aqui apresentada fez parte do projeto de pesquisa intitulado "Didática da História, Cultura Histórica e Indústria Cultural: Perspectivas desde e sobre a América Latina", e desenvolveu-se durante o curso extensão chamado "Ensinar e Aprender História", que é ofertado a professores de história do ensino fundamental e estudantes de graduação em História, Brasileiros e Paraguaios, na Universidade Federal da Integração Latino-Americana, localizada em Foz do Iguaçu-PR, na região da tríplice fronteira Brasil-Paraguai-Argentina. 
Durante o curso, realizou-se essa investigação visando confrontar as perspectivas de sujeitos de nacionalidades distintas sobre uma temática complexa no âmbito da cultura histórica: a Guerra da Tríplice Aliança, ou Guerra do Paraguai. Os objetivos do estudo foram três: 1. Observar que concepções de objetividade e perspectividade do conhecimento esses sujeitos mobilizam em suas ideias históricas; 2. Verificar possíveis diferenças entre os dois grupos da investigação: brasileiros e paraguaios; 3. Refletir sobre as relações entre racionalidade histórica e identidade histórica a partir das ideias históricas mobilizadas por esses sujeitos.

A investigação nasceu da articulação entre pesquisa-ensino-extensão. No contexto de um curso de extensão, ofertado a professores e estudantes de licenciatura em história brasileiros e paraguaios, foi possível desenvolver debates, estudos e projetos com vistas a difundir conceitos e problemáticas nas perspectivas da Didática da História e da Educação Histórica. Simultaneamente, esses mesmos indivíduos foram sujeitos de pesquisas, que visavam refletir sobre limites e possibilidades do pensamento histórico em suas interfaces com a cultura histórica, a consciência histórica e o conhecimento escolarizado.

O curso de extensão foi ofertado durante o ano de 2015, organizado a partir de alguns eixos teóricos, que eram seguidos por atividades práticas de investigação/intervenção em aulas de história. No contexto dessas atividades, emergiu uma problemática em relação à forma como a temática da Guerra do Paraguai, ou Guerra da Tríplice Aliança, é abordada no esnino de história e está presente na cultura histórica dos dois países vizinhos.

Essa questão ganhou maior força quando uma das professoras paraguaias participantes do curso, realizou um estudo exploratório, que revelou diferenças de perspectivas histórica de estudantes paraguaios e brasiguaios ${ }^{3}$ em uma escola no município de San Alberto, na província de Alto-Paraná. Do estudo exploratório desenvolvido pela professora, nasceu uma preocupação com relação às narrativas que os próprios participantes do curso difundiam com relação ao conflito. E, nesse mesmo quadro, foi possível levantar a problemática da relação entre a perspectividade das narrativas influenciadas pela cultura histórica de cada nação, e a necessidade de objetividade na formação do pensamento histórico.

Entre os participantes deste estudo, foi possível perceber distintos conhecimentos e opiniões sobre o conflito. Eram cinco cidadãs paraguaias, quatro professoras e uma estudante de licenciatura em história da Unila, e entre elas o assunto era abordado como algo muito familiar, como uma história efetivamente viva, que gerava uma preocupação constante com a relação dos acontecimentos passados com a condição de vida atual do Paraguai, entendido como um país em condição de inferioridade com relação ao Brasil devido à derrota na guerra.

\footnotetext{
${ }^{3}$ Brasiguaios é um termo utilizado para referir-se a colonos brasileiros que adquiriram terras e formaram comunidades em território paraguaio, especialmente em regiões próximas à fronteira com as regiões Oeste do estado do Paraná e Sudoeste do Mato Grosso do Sul.
} 
Já os sete brasileiros, duas professoras e cinco estudantes de licenciatura em história da Unila, demonstraram muito interesse pelos assuntos relacionados à guerra. Entretanto, era visível como pensavam nessa temática principalmente como problemas de reflexão histórica, e não como uma preocupação política do presente, ou seja, algo que desperta interesse pelo passado e não reflexões sobre o presente.

É importante enfatizar também que não há consenso sobre a Guerra da Tríplice Aliança no âmbito da historiografia, pois o tema foi tratado por vários especialistas, e questões importantes geram debates e divergências de opinião, como os motivos que levaram ao conflito e as responsabilidades dos países envolvidos (DORATIOTO, 2002).

À margem dos debates historiográficos mais recentes, os fatos relacionados à guerra são tratados de maneiras distintas nos dois países. No Paraguai, na cultura histórica nacional, trata-se o conflito como determinante para a identidade dos paraguaios, pois sustenta a concepção de uma herança maldita, que ainda hoje influencia a vida dos paraguaios e as condições de desenvolvimento do país. No Brasil o entendimento comum é que se trata de um momento importante para a história nacional, mas não com a mesma centralidade, e dificilmente se estabelece relações com a situação atual do país.

E, no Brasil, os fatos da guerra, geralmente, não são tratados como catastróficos ou traumáticos e, tanto na tradição de um "saber histórico escolar", como nos meios de comunicação, nota-se uma tímida narração dessa histórica como uma vitória que ajudou a construir a grandeza nacional, ainda que sem dar-se grande importância à crueldade do conflito, nem à sua centralidade em relação à configuração política regional na América do Sul, e muitas vezes silenciando esses aspectos (MOTA, 1995).

Já no Paraguai, tanto nas escolas, como nos meios de comunicação e nos pronunciamentos das autoridades políticas, parece central para o país manter viva a história da guerra. Em todos os níveis de educação existem conteúdos específicos para aprofundar o estudo da temática, que ocupam grande parte do currículo de história da escola básica. Há datas comemorativas, em nível nacional, que celebram memórias das batalhas e o heroísmo dos que lutaram, como símbolo da força e tenacidade dos paraguaios.

Essa realidade fomenta o rememorar constante da guerra, assim como uma relação de identificação com o país, gerando uma impressão de que os paraguaios são todos herdeiros de uma derrota injusta, numa luta sangrenta contra três nações vizinhas e inimigas. Por isso, é comum a noção segundo à qual o Paraguai e os paraguaios sofrem, ainda hoje, as consequências daqueles acontecimentos brutais, o que alimenta certo rancor para com os países vizinhos.

Durante o curso, optou-se por levantar essas questões, através de debates e proposições de atividades de reflexão sobre as causas do conflito, as perdas para todos os países 
envolvidos e a necessidade de se pensar no futuro e buscar uma integração regional mais amigável e efetiva. Isso tudo com uma especial atenção para os fundamentos do pensamento histórico, já debatidos aqui, como a aceitação da inevitabilidade da perspectividade, a exigência de critérios de análises das evidências históricas, e o tratamento adequado dos documentos, bem como avaliação da plausibilidade das inferências levantadas. Em síntese, foi realizado o trabalho de tentar organizar um debate coletivo sobre a guerra, mas com a intenção de superar a ideia de inimizade das nações e contribuir para novas narrativas, mais complexas e com vistas a um futuro conciliatório.

Ao final do curso, quanto todo esse trabalho havia se concluído, professores e estudantes foram convidados a participar desse estudo, que consistiu numa pequena investigação sobre como lidariam com versões narrativas conflituosas a respeito da guerra. Foi uma forma de avaliar os limites e possibilidades desse tipo de curso frente às identidades dos sujeitos, e ao mesmo tempo apresentar problemáticas para futuras investigações e intervenções.

Foi apresentado um conjunto de quatro textos pequenos, que explicavam as causas da guerra, mas a partir de perspectivas distintas e com explicações conflitivas. E, na sequência, foi aplicado um questionário com algumas perguntas, no sentido de entender como os participantes interpretavam as distintas explicações das causas da guerra, e se seria possível notar diferenças entre brasileiros e paraguaios em suas perspectivas sobre um mesmo objeto de análise. Ou seja, mesmo com o fato de todos eles terem participado do curso, a questão era verificar se as identidades nacionais e as distintas formações desses sujeitos, de alguma forma, os levariam a chegar a conclusões divergentes. Em síntese, o que se esperava era contribuir para entender a identidade histórica dos sujeitos como fator relevante para a formação de professores de História.

O instrumento de investigação utilizado consistiu em apresentar aos participantes do curso um conjunto de quatro textos curtos, extraídos de sites de internet e livros didáticos:

1. "A guerra do Paraguai foi o maior conflito armado internacional ocorrido na América do sul no século 19. Rivalidades platinas e a formação de Estados Nacionais deflagaram o confronto, que destruiu a economia e a população paraguaias" (GUERRA... 2015).

2. "En el Paraguay, el estado controlaba todo lo que se vendía a otros países. El principal producto de exportación era la yerba mate. Por ese motivo los brasileños que producían yerba mate perdieron mucho dinero, pues ellos vendían a un precio más elevado que la yerba en el Paraguay. En 1861 el gobernador de la Provincia de Rio 
Grande del Sur, fue a pedir al Parlamento Brasileño que se declare la guerra al Paraguay". (Extraído do livro didático paraguaio "La guerra contra la Triple Alianza").

3. "El factor desencadenante de la guerra de la Triple Alianza, el conflicto militar más sangrento y de más graves consecuencias en Sudamérica desde la independencia hasta hoy, fue el intento de un golpe de Estado en El Uruguay". (Extraído do livro didático paraguaio. POTTHAST, 2011).

4. "O conflito iniciou-se com a invasão da província brasileira de Mato Grosso pelo exército do Paraguai, sob ordens do presidente Francisco Solano López. O ataque paraguaio ocorreu após uma intervenção armada do Brasil no Uruguai, em 1864, que pôs fim à guerra civil uruguaia ao depor o presidente constitucional Atanasio Aguirre, do Partido Blanco, e empossar seu rival colorado, Venancio Flores, aliado de Bartolomé Mitre e do Império do Brasil. Solano López temia que o Império brasileiro e a República Argentina viessem a desmantelar os países menores do Cone Sul" (WIKIPÉDIA, 2016).

Como se pode notar, cada um dos textos define uma causalidade principal para a ecolsão do conflito. O primeiro texto cita rivalidades políticas na formação dos Estados Nacionais. O segundo ressalta as disputas econômicas pelo controle do coméricio da erva mate. O terceiro dá maior importância ao Golpe de Estado no Uruguai, como fato causador da guerra. E o ultimo texto responsabiliza Solano Lopes, o governante paraguaio, por iniciar o conflito, contudo justifica essa atitude como uma reação à ameação que o Brasil representava à soberania e ao desenvolvimento paraguaio.

Foram aplicadas cinco perguntas sobre os textos. Contudo, para as análises que se seguem, serão apresentadas apenas as respostas dadas a dois questionamentos: 1. Você considera alguma das explicações mais fiel à verdade histórica? Qual? 2. Algum desses textos conta alguma mentira ou esconde alguma informação? Qual? O que é ocultado?

Em relação aos textos utilizados, o importante não é fazer uma contextualização profunda ou uma análise de suas origens, como por exemplo o fato de serem extraídos de livros didáticos ou de sites de internet. A centralidade da investigação se situa na possiblidade de perceber múltiplas visões sobre a guerra na cultura histórica, e analisar como os doze participantes da investigação formularam conclusões a partir das perguntas realizadas. 
A apresentação dos dados obtidos a partir das respostas está expressa nas quadros abaixo, que separam as respostas de brasileiros e paraguaios, e define categorias de análise criadas a partir das reflexões teóricas apresentadas anteriormente neste texto, com ênfase nas duas perspectivas de objetividade histórica - nominalista e realista. É importante informar que as respostas foram simplificadas para facilitar a análise, e suas versões completas se encontram arquivadas na universidade onde a pesquisa foi realizada.

Quadro 1 - Respostas às questões dadas pelas cinco cidadãs paraguaias

\begin{tabular}{|c|c|c|c|c|}
\hline $\begin{array}{ll}\text { 1. Existe } & \text { uma } \\
\text { explicação } & \text { mais } \\
\text { verdadeira? } & \\
\text { Qual? } & \\
\end{array}$ & Por quê? & $\begin{array}{l}\text { 2. Algum dos } \\
\text { textos conta } \\
\text { alguma } \\
\text { mentira? } \\
\end{array}$ & $\begin{array}{lrr}\text { Qual é } & \text { a } \\
\text { mentira? } & \end{array}$ & $\begin{array}{l}\text { Perspectiva } \\
\text { de } \\
\text { objetividade } \\
\text { histórica: }\end{array}$ \\
\hline Não. & $\begin{array}{l}\text { Representam } \\
\text { interesses. }\end{array}$ & $\begin{array}{l}\text { Não é possível } \\
\text { saber }\end{array}$ & - & Nominalista \\
\hline Sim, o texto 4. & $\begin{array}{l}\text { Próximo do que já } \\
\text { conhecia. }\end{array}$ & $\begin{array}{l}\text { Não é possível } \\
\text { saber. }\end{array}$ & - & Realista \\
\hline Sim, o texto 4. & O mais adequado. & Sim, o texto 2. & $\begin{array}{l}\text { A causa } \text { da } \\
\text { guerra não } \\
\text { foi a Erva } \\
\text { Mate. } \\
\end{array}$ & Realista \\
\hline Sim, o texto 2. & $\begin{array}{l}\text { Próximo ao que } \\
\text { aprendeu } \\
\text { escola. }\end{array}$ & Sim, o texto 4. & $\begin{array}{l}\text { O Paraguai } \\
\text { nunca } \\
\text { invadiu } \quad \text { o } \\
\text { Brasil. }\end{array}$ & Realista \\
\hline $\begin{array}{l}\text { Sim, os textos } 1 \mathrm{e} \\
4 .\end{array}$ & $\begin{array}{l}\text { - Conta sobre a } \\
\text { destruição da } \\
\text { economia } \\
\text { paraguaia; } \\
\text { 4. Informa como o } \\
\text { Paraguai foi } \\
\text { invadido pelos } \\
\text { países vizinhos. } \\
\end{array}$ & Sim, o texto 2. & $\begin{array}{lr}0 & \text { maior } \\
\text { exportador } & \\
\text { de erva } & \text { mate } \\
\text { era } & \text { o } \\
\text { Paraguai, } & \text { e } \\
\text { não o Brasil. }\end{array}$ & Realista \\
\hline
\end{tabular}

Fonte: $\mathrm{O}$ autor. 
Quadro 2 - Respostas às questões dadas pelos sete cidadãos brasileiros

\begin{tabular}{|c|c|c|c|c|}
\hline $\begin{array}{l}\text { 1. Há uma } \\
\text { explicação } \\
\text { mais } \\
\text { verdadeira? } \\
\text { Qual? }\end{array}$ & Por quê? & $\begin{array}{l}\text { 2. Algum dos } \\
\text { textos conta } \\
\text { alguma } \\
\text { mentira? }\end{array}$ & $\begin{array}{l}\text { Qual é a } \\
\text { mentira? }\end{array}$ & $\begin{array}{l}\text { Perspectiva de } \\
\text { objetividade } \\
\text { histórica: }\end{array}$ \\
\hline Não & $\begin{array}{lr}\mathbf{E} & \text { necessário } \\
\text { conhecer } & \text { o contexto } \\
\text { no qual foi escrito. }\end{array}$ & $\begin{array}{l}\text { Resposta } \\
\text { divergente }^{*}\end{array}$ & & Nominalista \\
\hline Não & $\begin{array}{l}\text { Todos tem um fundo } \\
\text { de verdade. }\end{array}$ & $\begin{array}{l}\text { Pode ser que } \\
\text { sim. }\end{array}$ & No sabe decir & Realista \\
\hline Não & $\begin{array}{l}\text { São percepções, não } \\
\text { verdades. }\end{array}$ & $\begin{array}{l}\text { Resposta } \\
\text { divergente }\end{array}$ & & Nominalista \\
\hline Não & $\begin{array}{l}\text { Representam } \\
\text { perspectivas } \\
\text { distintas. } \\
\end{array}$ & $\begin{array}{l}\text { Resposta } \\
\text { divergente }\end{array}$ & & Nominalista \\
\hline Não & $\begin{array}{l}\text { Representam } \\
\text { perspectivas } \\
\text { distintas. }\end{array}$ & $\begin{array}{l}\text { Resposta } \\
\text { divergente }\end{array}$ & & Nominalista \\
\hline Não & $\begin{array}{l}\text { Representam } \\
\text { interesses distintos. }\end{array}$ & $\begin{array}{l}\text { Resposta } \\
\text { divergente }\end{array}$ & & Nominalista \\
\hline $\begin{array}{l}\text { Sim, os textos } \\
3 \text { e } 4 \text {. }\end{array}$ & $\begin{array}{ll}\text { Trazem } & \text { mais } \\
\text { informações. } & \end{array}$ & $\begin{array}{l}\text { Sim, os textos } 3 \\
\text { e } 4 \text {. }\end{array}$ & $\begin{array}{lr}\quad \text { texto } & 4 \\
\text { trata } & \text { o } \\
\text { Paraguai } & \\
\text { como única } \\
\text { vítima } \\
\text { guerra. }\end{array}$ & Realista \\
\hline
\end{tabular}

Fonte: O autor.

A informações contidas nas respostas dos participantes do estudo permitem algumas análises. A primeira, é que a maioria das paraguaias demonstra uma perspectiva realista de objetividade histórica, ou seja, entendem que os documentos podem se aproximar de uma verdade a respeito dos fatos passados. Enquanto entre os brasileiros, a situação é oposta, pois a maioria apresenta uma perspectiva nominalista, ou seja, a diversidade de explicações é própria da história e não é possível definir uma visão como mais verdadeira, pois todas são condicionadas a perspectivas ou interesses distintos. O que nos leva aos questionamentos:

Os resultados significam que os participantes brasileiros apreenderam melhor do que as paraguaias a concepção de multiperspectividade no pensamento histórico? Se caracterizarmos a perspectiva nominalista mais avançada que a realista, ainda que não apontando para uma perspectiva construtiva, a resposta seria afirmativa, ainda que superficial. Contudo, também podemos nos questionar se não se trata de um problema de

\footnotetext{
* O termo "resposta divergente" foi utilizado para categorizar respostas que não afirmavam que há erros de informação com relação às explicações, mas sim erros na estruturação dos argumentos. Por exemplo, em um dos casos foi respondido que o problema é que todas as explicações são muito simples, e por isso estão todas equivocadas.
} 
identidade e cultura histórica, e imaginar que se o tema fosse outro, ou se envolve-se maior número de indivíduos, poderíamos obter resultados diferentes. Como não foi realizado outro estudo para testar essas possibilidades, concentraremos as atenções em compreender os dados disponíveis.

Para aprofundar essa reflexão, a opção foi analisar as explicações contidas nas respostas. Entre as paraguaias, a visão a respeito da objetividade histórica é fundamentada a partir de uma preocupação que tem a ver com as formas como cada uma das explicações se relaciona com seus conhecimentos e sentimentos em relação à histórica em questão: proximidade com o que aprendeu na escola; proximidade com o que já conhecia; Além disso, como tratam a centralidade do Paraguai como vítima da guerra: conta a destruição da economia paraguaia; informa que o Paraguai foi vítima dos países vizinhos.

A única cidadã paraguaia, entre as participantes dessa investigação, que deu uma resposta diferente das demais, dizendo que todas as explicações representam interesses, foi uma estudante de licenciatura em História que mora e estuda no Brasil. As demais são professoras paraguaias que vivem em seu país. E, por outro lado, entre os brasileiros, a única resposta em favor da ideia que é possível uma explicação histórica mais verdadeira, trouxe a explicação que isso tem a ver com a quantidade de informações, e não com as informações expressas no estudo.

A problemática que se apresenta é o duplo enquadramento do conceito histórico Guerra da Tríplice Aliança, ou Guerra do Paraguai, no âmbito da cultura histórica, e como os resultados da investigação apontam para uma força cognitiva da identidade histórica, que se apresenta como obstáculo à aprendizagem das categorias históricas fundadas numa noção de racionalidade pura.

Pensando nessa problemática, da relação estreita entre aprendizagem histórica e orientação da vida, Bodo Von Borries (2011), definiu o conceito de Burdening History. Apesar da tradução literal do termo não clarear seu sentido, é possível sintetizá -la a partir da noção de "carga" ou "fardo". Nesse caso, o tema de reflexão seria a necessidade de se lidar com uma história que tem uma sobrecarga de emoções e de complexidades, pois trata de temas relevantes e impactantes no âmbito da cultura histórica e da aprendizagem histórica .

Obviamente, utilizar o conceito de Burdening History para analisar a relação que os paraguaios estabelecem com a história da Guerra da Tríplice Aliança pode ser arriscado, pois no contexto da Didática da História na Alemanha, essa problemátização decorre da necessidade de enfrentamento do trauma que a sociedade alemã estabelece, particularmente, com a história do Nazismo e do Holocausto.

Nos seus estudos sobre a aprendizagem dos jovens alemães quando lidam com temas históricos "sobrecarregados", como o nazismo e o Holocausto, Bodo Von Borries (2011) 
observou como esses assuntos são traumáticos para aqueles estudantes e envolvem mais do que simplesmente se aprofundar o assunto. A herança negativa o período nazista e o Holocausto trazem para a identidade histórica alemã insere os jovens num processo que não é apenas intelectual, mas envolve questões identitárias, culturais e emocionais.

No caso alemão, Von Borries (2011) identifica uma prática de culpabilização dos cidadãos pelos crimes nazistas, que envolve a sociedade como um todo, e não apenas herdeiros dos comandantes do regime ou daqueles que se beneficiaram daqueles eventos. Dessa forma, a consciência histórica dos alemães continua abalada pelo mal-estar provocado com a lembrança constante do Holocausto, o que torna o tema traumático para ser trabalhado com os jovens no ensino de História.

Mas se o conceito de Burdenin History é utilizado para definir determinadas temáticas históricas que remetem a acontecimentos que têm grande peso no presente e, por isso, exigem um tratamento específico, pois não envolve apenas o aprendizado do que se passou, mas também de quais são as decisões a serem tomadas a partir do que se passou. É possível inferir que a história da Guerra da Tríplice Aliança, especialmente para os cidadãos paraguaios, é uma problemática presente e sobrecarregada.

Segundo Von Borries (2011), três problemas são recorrentes nessa história "sobrecarregada": a incessante necessidade de se definir culpados, a responsabilização coletiva da sociedade e a vergonha que ela provoca. No caso em questão, o que se apresenta como diferença é o fato que a responsabilização coletiva é sempre do outro, ou seja, o fardo não é lidar com a culpa, mas uma certa espectativa de "justiçamento histórico", ou de provar aos outros que eles têm a culpa. E, ainda, ao invés de vergonha, o que se apresenta é o orgulho de pertencer aos injustiçados, e a ânsia de narrar essa história como forma de fortalecimento das identidades. Um quarto ponto que caracteriza essa história "sobrecarregada", é o sentimento de luto contínuo, uma rememoração que impede que essa experiência seja esquecida ou reprimida.

Mesmo levando-se em conta que não estamos tratando de um tema com a mesma "sobrecarga" que o Nazismo tem para os alemães, inferimos que a Guerra da Tríplice Aliança é uma história sobrecarregada para os paraguaios, pois remete a emoções e sentimentos, e constitui-se como desafio à aprendizagem histórica com uma expectativa construtiva de futuro. O futuro sempre remete a uma revitalização do passado, ou seja, a inversão histórica é mais importante do que a superação do trauma.

Bodo Von Borries define que, para a História ser efetivamente aprendida, é necessário que as seguintes condições se façam presentes: 1. Se novos conhecimentos puderem fazer relações com os já adquiridos; 2. Se tais conhecimentos estiverem conectados à emoções negativas ou positivas e; 3. Se forem relevantes para vida dos sujeitos. Nesse sentido, a 
questão da burderning history é uma importante contribuição desse pesquisador, pois revela como os temas de alta complexidade podem ser significativos na aprendizagem histórica.

Para lidar com essa história traumática, Von Borries afirma que existem formas produtivas e formas deficitárias. Dentre as formas deficitárias, são apontadas: 1. Inimizade herdada: quando as novas gerações se envolvem na busca constante por sistemas de vingança; 2. Cinismo do poder: quando há a omissão deliberada ou esquecimento dos derrotados, através da exaltação da história dos vencedores; 3. Heroísmo da lembrança: ocorre quando os derrotados cultivam esse passado como alimento espiritual para uma possível inversão histórica; 4. Prioridade da sobrevivência: a história passa a ser negada ou esquecida, perde seu sentido, criando-se uma prática anti-histórica.

Tais formas de lidar com a história traumática são consideradas deficitárias porque fazem conexões inadequadas com o passado. A sociedade, envolvida emocionalmente, esteticamente e politicamente com esse passado, adota formas de manuseá-lo para gerar efeitos no presente. Nesses casos, tais histórias, ao invés de superadas, cumprem funções culturais decisivas, levando as novas gerações a formas perigosas de lidar com o passado, pois ele fica mal resolvido, tornando-se potencializador de conflitos.

Von Borries (2011) argumenta que a opção, nesse caso, é buscar as chamadas estratégias de reconciliação histórica. Essa reconciliação não se se trataria apenas de um processo histórico-cognitivo, ou seja, de um processo de busca por uma racionalidade mais profunda na narração do passado. Mas também um processo social-histórico e emocional histórico, ou seja, envolve a participação dos sujeitos e o desenvolvimento de relações intersubjetivas de reconhecimento das identidades e valorização do outro.

Para esse encontro com o outro, seriam necessárias pré-condições mentais que exigem grande esforço para serem desenvolvidas, entre elas: Tomar distância do passado sem esquecê-lo; Não permitir que o passado determine completamente o presente; Observas as condições e oportunidades de um futuro comum. Assim, cada lado teria a oportunidade de observar os hábitos do outro lado e antecipar suas reações, evitando os simples padrões exemplares e tradicionais de construção de sentido tentando alcançar os patamares críticos e genéticos de orientação histórica (Rüsen, 2012).

O presente trabalho não se propõe a resolver a questão da relação que os paraguaios e brasileiros estabelecem com a história da Guerra da Tríplice Aliança, primeiramente porque não é o objeto central do artigo, e também porque, para isso, seria necessário construir um arcabouço de pesquisa e fundamentação teórica bem mais amplo e aprofundado. Sendo assim, a reflexão sobre a Burdening History se apresenta como um guia teórico para direcionar alguns olhares sobre as questões manifestadas no estudo empírico, e abrir possibilidade para o avanço das pesquisas nessa direção. 
A efetiva contribuição deste estudo é questionar a ideia de que a progressão da aprendizagem conceitual da história seria suficiente para significar uma efetiva orientação da vida prática. Isso se partirmos da visão limitada de conceitos históricos analíticos descolados da relação com as identidades dos sujeitos. Tendo esse referencial, pode-se inferir que os brasileiros que participaram do estudo mobilizaram uma visão mais sofisticada da história da Guerra da Tríplice Aliança. Contudo, essa sofisticação pode significar indiferença quanto ao peso desse passado, e um descomprometimento com apontar soluções para as diferenças de interpretação que provocam conflitos de perspectivas entre brasileiros e paraguaios, que podem originar outros conflitos. Ou seja, o reconhecimento da multiperspectividade pode ser o desinteresse por esse passado, que leva ao relativismo.

A Guerra da Tríplice Aliança é um tema em aberto na cultura histórica, e de uma central relevância para quem vive nas regiões fronteira e convive com a situação incômoda herdada das concepções de rivalidade nacional historicamente construídas. Enquanto entre os brasileiros, fica clara uma opção por uma ideia aparentemente "neutra" de lidar com esse passado, pela via da busca por uma objetividade isenta do historiador, entre os paraguaios esse passado se mantém vivo, com certa dose de rancor e revanchismo.

Como já foi dito, nos limites deste artigo, não se pode apontar quais são as alternativas para superar esse quadro. Ele envolve todo um conjunto de práticas e conhecimentos em relação ao passado, que passa pela historiografia acadêmica, pela cultura escolar e pelas políticas de Estado. Contudo, ressaltamos que essa problemática traz uma contribuição teórica, pois corrobora com a concepção de que a busca por uma aprendizagem histórica qualificada por critérios de racionalidade não pode ignorar os efeitos que essa história tem na vida dos sujeitos, nem os limites impostos pelas relações identitárias e afetivas com a história.

\section{Considerações finais}

Este artigo parte de indagações teóricas, que se estruturam e afunilam-se até chegar na problemática do estudo empírico realizado, que foi a relação que os sujeitos estabelecem com o passado e a possibilidade de utilizarem categorias históricas que epistemologicamente as possibilidades de compreensão do passado, quando esse passado diz respeito às suas identidades consolidadas no âmbito da cultura histórica nacional. 
Inicialmente, gostaria de reconhecer as limitações da estratégia metodológica adotada, tanto por sua pouca abrangência quanto ao número de sujeitos participantes da pesquisa, quanto pela relação de autoria que o pesquisador estabelceu com o objeto da pesquisa. Ou seja, por tratar-se de um estudo sobre ideias históricas de sujeitos que passaram por um curso de formação ofertado pelo próprio pesquisador, essa pesquisa pode sofrer com a limitação do olhar do sujeito pesquisador.

Contudo, defendo que algumas constatações desse trabalho são válidas para apontar possibilidades de aprondamento, tanto teórico quanto empírico. Sendo assim, a conclusão provisória a que se pode chegar com esse breve estudo é que a percepção de objetividade e perspectividade da história tem a ver também com a proximidade ou distância dos sujeitos em relação aos temas abordados. Esse relacionamento se constitui na formação das identidades e nas práticas e percepções no âmbito da cultura histórica.

Se entre quatro professoras paraguaias a questão da multiperspectividade não foi compreendida a partir da ideia de que todas as explicações são equivalentes, infere-se que isso tem a ver com a maneira como essas questões afetavam suas identidades e com a importância que davam aos fatos relatados. Já entre os brasileiros, é possível notar como é mais fácil tratar da ideia de multiperspectividade como diversidade de pontos de vista, pois esse assunto não os afeta em suas convicções ou identidades.

Contudo, conforme as proposições teóricas assinaladas, essa fundamentação da objetividade histórica, e a aceitação da multiperspectividade, necessitam estar embasadas em três critérios para converter-se em construtiva: pertinência empírica, pertinência normativa e pertinência narrativa. $\mathrm{O}$ debate sobre quais narrativas sobre a guerra seriam pertinentes, no sentido de buscar uma conciliação histórica com as identidades dos sujeitos, é um caminho por ser trilhado. Estudos qualitativos como esse permitem inferir problemáticas e iniciar um caminho investigativo com expectativas mais ambiciosas.

Enfim, essa foi uma investigação muito pontual, e que buscou percepções iniciais para tentear responder às problemáticas apresentadas. Ainda assim, é possível formular duas ideias para investigações futuras: 1. É importante enfrentar a problemática das implicações da objetividade / perspectividade histórica no âmbito da construção de explicações históricas com expectativas de futuro; 2. Não é suficiente aprender conceitos epistemológicos da ciência histórica, pois deve-se também levar em consideração a consciência histórica dos sujeitos, ou seja, compreender quais são as maneiras pelas quais utilizam determinadas narrativas sobre o passado para dar sentido a suas identidades e ações no mundo; 3. É fundamental buscar na cultura histórica os conteúdos fundadores de nova uma pragmática do ensino, da aprendizagem e da formação histórica. Especialmente de uma formação que se oriente pelas finalidades de desenvolver a análise, a argumentação e a qualificação das narrativas no âmbito da cultura histórica, e a busca por alternativas coletivas de reconciliação histórica. 


\section{Referências}

ADORNO, Theodor W. Teoria da Semicultura. Trad. Newton Ramos-de-Oliveira, Bruno Pucci e Cláudia B. M. de Abreu. Revista Educação e Sociedade, ano 17, n. 56, p. 388-411, dez. 1996.

ASHBY, Rosalyn. Desenvolvendo um conceito de evidência histórica: as ideias dos estudantes sobre testar afirmações factuais singulares. In: SCHMIDT, Maria Auxiliadora; GARCIA, Tânia Braga (Org.). Educar em Revista. Curitiba, n. esp., p. 151-170, ago. 2006.

BERGMANN, Klaus. A história na reflexão didática. In: Revista Brasileira de História, São Paulo, v. 9, n. 19, p. 29-42, set. 1989/fev. 1990.

DORATIOTO, Francisco F.; MONTEOLIVA. Maldita Guerra: nova histórica da Guerra do Paraguai. São Paulo: Cia das Letras, 2002.

GERMINARI, Geyso D. Educação Histórica: a construção de um campo de pesquisa. Revista HISTEDBR On-Line, Campinas, n. 42, p. 54-70, jun. 2011.

GUERRA do Paraguai. Só História: Disponível em: <http://www.sohistoria.com.br/ ef2/guerraparaguai/>. Acesso em: 11 out. 2015.

LEE, Peter. Em direção a um conceito de literacia histórica. Educar em Revista. Curitiba, n. esp., p. 131-150, 2006.

. Historical literacy and transformative history. In: SHELMIT, Denis; PERIKLEOUS, Lukas (Ed.). The future of the past: why history educations matters. Nicosia: UNDP-ACT, Cyprus, 2011. p. 129-168.

MÈSZAROS, István. A educação para além do capital. São Paulo: Boitempo, 2008.

MOTA, Carlos G. História de um silêncio: a guerra contra o Paraguai (1864-1870) 130 anos depois. Estudos Avançados, São Paulo, v. 9, n. 24, p. 243-254, Aug. 1995.

POTTHAST, Bárbara. Paraíso de Mahoma" o "País de las mujeres"? : El rol de la familia en la sociedad paraguaya del siglo XIX. Asunción: Fausto Editor, 2011.

REIS, José Carlos. História e teoria: historicismo, modernidade, temporalidade e verda de. 3. ed. Rio de Janeiro: Ed. FGV, 2006.

RÜSEN, Jörn. Razão histórica. teoria da história: os fundamentos da ciência histórica. Brasília: UNB, 2001. 
História viva. Teoria da história III: formas e funções do conhecimento histórico. Tradução de Estevão Rezende Martins. Brasília: Ed. UNB, 2007.

_._. _. O que é formação Histórica? In: SCHMIDT, Maria Auxiliadora; BARCA, Isabel; MARTINS Estevão de Rezende (Org.). Jörn Rüsen e o ensino de história. Curitiba: Ed. UFPR, 2010.

SCHMIDT, Maria Auxiliadora; BARCA, Isabel (Org.). Aprender história: perspectivas da educação histórica. Ijuí: Ed. Unijuí, 2009.

SCHMIDT, Maria Auxiliadora. Cognição Histórica Situada: Que aprendizagem histórica é esta? In: SCHMIDT, Maria Auxiliadora; BARCA, Isabel. Aprender história: perspectivas da educação histórica. Ijuí: Ed. Unijuí, 2009.

VON BORRIES, Bodo. Competence of the historical thinking, mastering of a historical framework, or knowledge of historical canon? In: SYMCOX, Linda; WILSCHUT, Arie. National history standards: the problem of the canon and the future of teatching history. Charlotte: Internationa Review of History Education, 2009. p. 283-306.

- - _... Coping with Burdening history. In: BJERG, Helle; LENZ, Claudia; Thorstensen, Erik. (Eds.). Historicizing the uses of the past: scandinavian perspectives on history culture, historical consciousness and didactics of history related to world war II. Bielefeld, 2011. p. 165-188.

Competência do pensamento histórico, domínio de um panorama histórico, ou conhecimento do cânone histórico? Tradução Éder C. de Souza. Revista de Educação Histórica - REDUH, n.1. p. 155-178, jul./nov., 2012.

WIKIPÉDIA. Guerra do Paraguai. 2016. Disponível em: $<$ https://pt.wikipedia.org/wiki/Guerra_do_Paraguai>. Acesso em: 10 abr. 2017.

Recebido em 07.08.2016

Aprovado em 17.10.2016 